\title{
Morangos embalados com filme de Ppolicloreto de Vinila (PVC) ${ }^{1}$
}

\section{Strawberries packaged with Polyvinyl Chloride (PVC) film}

\author{
Fábio Yamashita ${ }^{2 *}$, Guilherme Ferrari Veiga ${ }^{3}$, \\ Marta de Toledo Benassi ${ }^{4}$, Sergio Ruffo Roberto ${ }^{5}$
}

Resumo

Foram utilizados morangos cv. Dover com aproximadamente $75 \%$ de sua superfície com coloração vermelha e embalados em potes de polietileno tereftalato (PET). No tratamento CONTROLE os morangos foram acondicionados sem filme e no tratamento FILME, as embalagens foram seladas com filme de PVC de $15 \mathrm{~mm}$ de espessura. As frutas foram armazenadas a $12^{\circ} \mathrm{C}$ por dez dias e foram determinadas ao longo do tempo acidez titulável, sólidos solúveis, vitamina $\mathrm{C}$, cor, taxa de respiração, textura e perda de massa. Após 6 dias de armazenagem os morangos CONTROLE estavam impróprios para consumo pois apresentavam deterioração visível por bolores enquanto que os embalados com PVC estavam em condições de consumo e comercialização. Após 10 dias todos os morangos estavam impróprios para consumo. A embalagem utilizando filme de PVC aumentou a vida de prateleira de morangos em relação aos sem embalagem pois preservou melhor a coloração característica do produto e teor de vitamina $\mathrm{C}$ e reduziu as taxas de respiração e de perda de massa, caracterizando a embalagem como sendo adequada para este tipo de produto.

Palavras-chave: pós-colheita, vida de prateleira, Fragaria x ananassa Duch

\begin{abstract}
Strawberries cv. Dover with approximately $75 \%$ of their surface with red color was packaged in disposable polyethylene terephthalate (PET) container and sealed with PVC film of $15 \mathrm{~mm}$ thick. Strawberries without film serves as control. The fruits were stored at $12^{\circ} \mathrm{C}$ for ten days and there were determined during storage time the titratable acidity, solid soluble and vitamin $\mathrm{C}$ contents, color, respiration rate, texture and weight loss. After 6 days the strawberries packaged without film had decayed while the fruits packaged with PVC film were in conditions of consumption and commercialization. After 10 days all fruits were inappropriate to consumption. Packages with PVC film extended the shelf life of strawberries preserving the color characteristic of the product and vitamin $\mathrm{C}$ content, reducing the respiration rate and weight loss, characterizing this packaging as being adequate to this kind of product.
\end{abstract}

Keywords: postharvest, shelf-life, Fragaria x ananassa Duch

1 Parte integrante do projeto de pesquisa do primeiro autor

Prof. Dr., TAM/UEL, CP 6001, 86051-990, Londrina-PR

Químico-UELguiveiga@yahoo.com.br

4 Prof. Dr., TAM/UEL, CP 6001, 86051-990, Londrina-PR

5 Prof. Dr., AGRONOMIA/UEL, CP 6001, 86051-990, Londrina-PR

* Autor a quem correspondência deve ser enviada

Recebido para publicação 08/02/06 Aprovado em 05/06/06 


\section{Introdução}

O morango (Fragaria $x$ ananassa Duch) é produzido e apreciado nas mais variadas regiões do mundo, sendo a espécie do grupo das pequenas frutas de maior expressão econômica. Além disso, trata-se de uma cultura de grande importância social, em função da grande demanda de mão-de-obra e do elevado rendimento por área (RESENDE et al., 1999).

No Brasil, a cultura do morangueiro ocupa uma área estimada de 3.600 ha, com produção em torno de 90 mil toneladas por ano, sendo os Estados de Minas Gerais (32,3\%), São Paulo $(31,4 \%)$ e Rio Grande do Sul (16,5\%) os maiores produtores. As propriedades que se dedicam ao cultivo do morangueiro são, em sua grande maioria, familiares, com área cultivada de 0,5 a 1,0 ha. Porém, também existem empresas com áreas cultivadas superiores a 8 ha (REICHERT; MADAIL, 2003).

O uso de materiais plásticos nas embalagens de alimentos tem aumentado no decorrer dos últimos anos, substituindo embalagens tradicionais de vidro, metal e papel, pelo seu custo, versatilidade e segurança (SARANTOPOULOS et al., 2001). Os filmes de policloreto de vinila (PVC) são largamente empregados na embalagem de frutas e hortaliças in natura e minimamente processadas, pois impedem a desidratação do produto, sendo de fácil manipulação e baixo custo.

O filme de PVC permite que se forme uma atmosfera modificada no interior da embalagem com alto teor de dióxido de carbono e baixas concentrações de oxigênio, reduzindo a taxa de respiração do produto e aumentando a sua vida de prateleira sem causar injúrias fisiológicas por anaerobiose (KLUGE et al., 1999; YAMASHITA et al., 2001; PFAFFENBACH, 2003). Elevadas concentrações de $\mathrm{CO}_{2}$, em torno de $30 \%$, podem afetar a coloração vermelha (antocianinas) nas superfícies dos tecidos de morangos após dois dias ou mais (KADER, 1986).
O desenvolvimento de microrganismos, tais como fungos e bactérias, também podem alterar a taxa de respiração de frutas. Os frutos contêm excelentes substratos para o desenvolvimento de microrganismos, como açúcares, ácidos, vitaminas e água. Em se tratando de microrganismos estritamente aeróbicos, o ataque por fungos pode ser reduzido utilizando baixas concentrações de $\mathrm{O}_{2}$ ou altos níveis de $\mathrm{CO}_{2}$ na atmosfera de armazenagem (CHITARRA; CHITARRA， 1990; KLUGE; NACHTIGAL, 1997).

Morangos armazenados por dois dias a $24^{\circ} \mathrm{C}$ conservaram $90 \%$ do teor de ácido ascórbico que existia no momento da colheita. No entanto, com o aumento do período de conservação, o conteúdo também foi reduzido (RONQUE, 1998).

Este trabalho teve como objetivo verificar a influência de embalagem com filmes de PVC sobre a vida de prateleira e características físico-químicas de morangos armazenados sob refrigeração.

\section{Material e Métodos}

\section{Material}

Foram utilizados morangos cv. Dover produzidos na região de Londrina PR e os frutos selecionados apresentavam estágio de maturação completo, possuíam mais de $75 \%$ de sua superfície com coloração vermelha característica, superfície regular e tamanho homogêneo, além da ausência de deterioração e danos físicos. Os frutos não sofreram tratamento fitossanitário.

Foram utilizados potes retangulares de polietileno tereftalato (PET) com $170 \mathrm{~mm} \times 100 \mathrm{~mm} \times 50 \mathrm{~mm}$ para acondicionar os morangos. Em cada pote foram acondicionados aproximadamente $300 \mathrm{~g}$ de morangos previamente selecionados. No tratamento CONTROLE os morangos foram acondicionados sem filme e no tratamento FILME, as embalagens foram seladas com filme de policloreto de vinila (PVC) com $15 \mathrm{~mm}$ de espessura. As frutas de ambos tratamentos foram armazenadas em estufa para 
B.O.D. (Marconi, modelo MA 415, Brasil) a $12^{\circ} \mathrm{C}$ com umidade relativa de $78 \pm 3 \%$ por dez dias.

\section{Métodos}

Foram determinadas as taxas de respiração, textura, perda de massa, acidez total titulável, teor de sólidos solúveis totais, teor de vitamina $\mathrm{C}$ e cor das amostras de morango dos tratamentos CONTROLE e FILME ao longo do tempo de armazenagem a $12^{\circ} \mathrm{C}$ a cada 3 ou quatro dias. Todas as análises foram realizadas em duplicata utilizando dois potes por tratamento.

\section{Taxa de Respiração}

O método de determinação foi baseado na capacidade de soluções básicas reagirem com $\mathrm{CO}_{2}$, retendo-o em solução na forma de íon carbonato de acordo com descrito por JACOMETTI et al. (2003). A taxa de respiração foi expressa em $\mathrm{mg} \mathrm{CO}_{2}$ por $\mathrm{kg}$ de morango por hora e foram descartadas as determinações das primeiras 24 horas para garantir que a temperatura do morango tivesse atingido $12^{\circ} \mathrm{C}$ e que o material não estivesse sob o estresse póscolheita, devido à manipulação e também que a composição gasosa no interior da embalagem tivesse atingido o equilíbrio.

\section{Firmeza}

A textura dos morangos foi avaliada através do atributo de firmeza, representado pelo pico máximo do gráfico de força versus distância, obtido num texturômetro (Stable Micro System, modelo TA XT2i, Inglaterra) acoplado a um microcomputador. Com o auxílio do software Texture Expert (versão 1.22) foram obtidos os valores de força máxima de esmagamento das amostras. Utilizou-se um "probe" cilíndrico de acrílico (P25L) de 25mm de diâmetro que comprimiu morangos cortados pela metade, no sentido longitudinal, até $50 \%$ de sua altura a uma velocidade de $5,0 \mathrm{~mm} / \mathrm{s}$. Cinco frutos de cada tratamento foram cortados totalizando 10 amostras de cada tratamento.

\section{Perda de Massa}

A perda de massa durante a armazenagem foi calculada em gramas/100 gramas da massa inicial do fruto. As pesagens foram feitas a cada 2 dias até o décimo dia de armazenagem, utilizando uma balança semi-analítica.

\section{Acidez Total Titulável e Teor de Sólidos Solúveis Totais}

A acidez total titulável e os sólidos solúveis totais foram determinados de acordo com as Normas Analíticas do INSTITUTO ADOLFO LUTZ (1985). A acidez titulável foi expressa em porcentagem de ácido cítrico e os sólidos solúveis em ${ }^{\circ}$ Brix, utilizandose um refratômetro de bancada (Carl Zeiss, modelo Abbe, Alemanha).

\section{Teor de Vitamina $C$}

O teor de vitamina C (ácido ascórbico) foi determinado pelo método padrão da AOAC (1984) modificado por BENASSI \& ANTUNES (1988). Amostras de $25 \mathrm{~g}$ de morango foram trituradas e homogeneizadas em $50 \mathrm{~g}$ de solução de ácido oxálico $2 \%$ (solução extratora). Retiraram-se $20 \mathrm{~g}$ deste extrato e completou-se o volume num balão volumétrico de $50 \mathrm{~mL}$ com a solução extratora. Tomou-se uma alíquota de $10 \mathrm{~mL}$ e titulou-se com 2,6-diclorofenolindofenol $0,01 \%$ previamente padronizado com solução padrão de ácido ascórbico.

\section{Cor}

Para a determinação da cor das amostras foi utilizado um colorímetro (Minolta, modelo CR-10, Japão) que vem calibrado de fábrica, que fornecia os parâmetros L*, a* e b* do sistema CIELAB. Com a aplicação da Equação 1, pode-se calcular a 
diferença de cor (DE) entre a amostra no tempo zero $\left(\mathrm{L}_{0}{ }^{*}, \mathrm{a}_{0}{ }^{*} \mathrm{e} \mathrm{b}_{0}{ }^{*}\right)$ e as amostras armazenadas nos diversos tempos.

$$
\Delta E=\sqrt{\left(L^{*}-L_{0}^{*}\right)^{2}+\left(a^{*}-a_{0}^{*}\right)^{2}+\left(b^{*}-b_{0}^{*}\right)^{2}}
$$

\section{Resultados E Discussão}

\section{Taxa de Respiração}

A taxa de respiração dos morangos embalados com filme de PVC foi $50 \pm 8 \mathrm{mg} \mathrm{CO}_{2} / \mathrm{kg}$.h e $71 \pm 7 \mathrm{mg}$ $\mathrm{CO}_{2} / \mathrm{kg}$.h dos morangos do tratamento controle. Considerando-se que a composição gasosa no interior da embalagem tivesse atingido o equilíbrio em 24 horas, devido ao pequeno espaço livre no interior da mesma, a taxa de respiração dos morangos embalados foi $40 \%$ menor que os morangos do tratamento controle, ou seja, a embalagem de PVC diminuiu a atividade metabólica do fruto. Esta redução da taxa de respiração foi devido a barreira formada pelo filme de PVC, que permitiu a criação de uma atmosfera modificada no interior da embalagem com alta concentração de $\mathrm{CO}_{2}$ e baixa concentração de $\mathrm{O}_{2}$ sem causar injúria ao produto por anaerobiose (KLUGE et al., 1999; YAMASHITA et al., 2000 e 2001; PFAFFENBACH, 2003).

\section{Firmeza}

Os valores de firmeza das amostras de morango embalados com e sem filme de PVC estão mostradas na Tabela 1 .

Tabela 1. Firmeza das amostras de morango armazenadas a $12^{\circ} \mathrm{C}$ por 10 dias

\begin{tabular}{ccc}
\hline \multirow{2}{*}{$\begin{array}{c}\text { Tempo } \\
\text { (dia) }\end{array}$} & \multicolumn{2}{c}{ Firmeza $(\mathrm{N})^{*}$} \\
\cline { 2 - 3 } & $\begin{array}{c}\text { Tratamento } \\
\text { CONTROLE }\end{array}$ & $\begin{array}{c}\text { Tratamento } \\
\text { FILME }\end{array}$ \\
\hline 0 & $39 \pm 12$ & $39 \pm 12$ \\
3 & $21 \pm 10$ & $22 \pm 8$ \\
6 & $37 \pm 12$ & $27 \pm 9$ \\
10 & $19 \pm 3$ & $22 \pm 10$ \\
\hline
\end{tabular}

* Média de 10 amostras \pm desvio padrão
Pode-se observar na Tabela 1 que houve uma grande variabilidade dos dados de firmeza, apesar dos morangos terem sido selecionados em termos de tamanho e grau de maturação. Desta forma não foi possível observar-se a influência dos tratamentos sobre a textura dos morangos ao longo do tempo de armazenagem a $12^{\circ} \mathrm{C}$.

\section{Perda de Massa}

Os morangos sem embalagem perderam $15 \%$ da massa inicial após 10 dias de armazenagem a $12^{\circ} \mathrm{C}$, enquanto que os embalados perderam apenas $6 \% \mathrm{e}$ a perda de massa apresentou comportamento linear em função do tempo. Por regressão linear dos dados de perda de massa em função do tempo foram obtidas equações do tipo perda de massa $=\mathrm{A}+$ B.tempo, com coeficientes de determinação $\left(\mathrm{R}^{2}\right)$ superiores a 0,97 e níveis de significância (p) menores que 0,05 , onde o parâmetro $\mathrm{B}$ é a taxa de perda de massa. As amostras do tratamento CONTROLE apresentaram taxa de perda de massa cerca de 2,5 vezes maior do que as amostras do tratamento FILME, 1,51 e 0,60g/100g, respectivamente. A perda de massa em frutos é devida principalmente à transpiração e o filme de PVC, como é barreira ao vapor de água, reduziu a taxa de perda de massa do morango pois criou-se no interior da embalagem uma atmosfera com alta umidade relativa, diminuindo o déficit de pressão de vapor de água e conseqüentemente a taxa de transpiração. Os morangos CONTROLE estavam sujeitos à umidade relativa no interior da estufa de armazenagem que foi de aproximadamente $78 \%$.

\section{Acidez Total Titulável e Teor de Sólidos Solúveis}

A variação da acidez titulável e do teor de sólidos solúveis das amostras de morango ao longo da armazenagem está na Figura 1. 


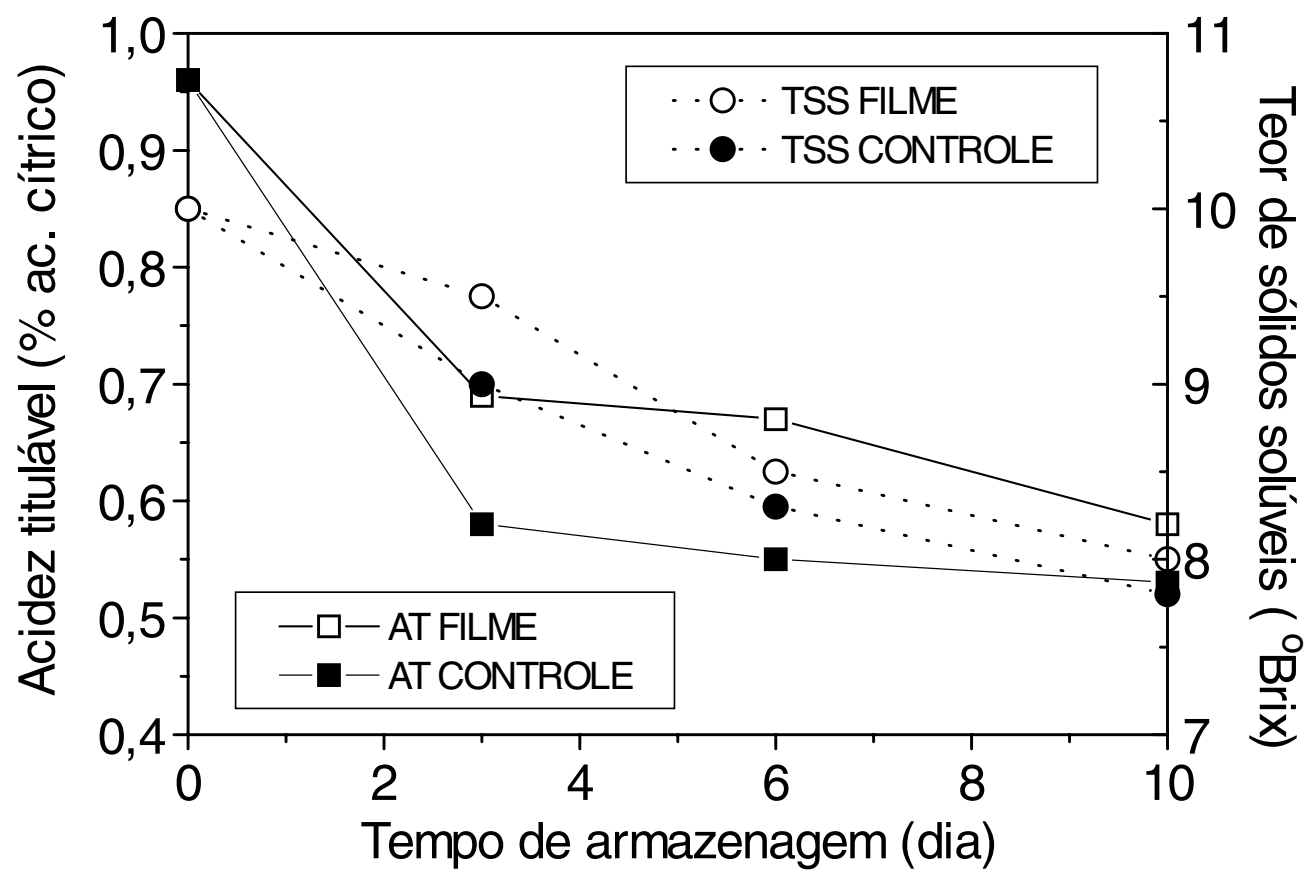

Figura 1. Acidez total titulável (AT) e teor de sólidos solúveis totais (TSS) dos morangos com e sem embalagem de PVC armazenados a $12^{\circ} \mathrm{C}$.

Pode-se observar que os frutos do tratamento CONTROLE apresentaram menor teor de ácido cítrico com o decorrer dos dias de armazenamento quando comparados aos frutos do tratamento FILME. Os ácidos orgânicos tendem a diminuir, em virtude da utilização dos mesmos como substrato para a respiração (NUNES \& MORAIS, 1995), sendo este comportamento observado no experimento, e como o filme reduziu a atividade metabólica, os frutos apresentaram maior acidez titulável em relação ao tratamento CONTROLE.

Houve uma diminuição do teor de sólidos solúveis com o decorrer do tempo de armazenagem pois os frutos utilizam açúcares como fonte de energia para manter a atividade metabólica. Os morangos do tratamento CONTROLE apresentaram valores inferiores de sólidos solúveis em relação aos do tratamento FILME devido a sua maior atividade metabólica. A diferença não foi maior pois a perda de massa do tratamento CONTROLE foi maior que o do FILME, isto é, quanto maior a perda de massa, maior a concentração dos sólidos solúveis.

\section{Teor de Vitamina $C$}

Os teores de vitamina $\mathrm{C}$ dos morangos ao longo da armazenagem estão expressos na Figura 2.

Houve uma diminuição gradual dos teores de vitamina $\mathrm{C}$ das amostras de morango ao decorrer do tempo em ambos os tratamentos. CALEGARO et al. (2002) observaram uma diminuição dos teores de vitamina $\mathrm{C}$ de amostras de morangos armazenados durante 14 dias, citando que a determinação do conteúdo de ácido ascórbico em vegetais é importante, pois, sendo a vitamina mais susceptível à degradação, sua presença no alimento indica que provavelmente os demais nutrientes também estão sendo preservados. 


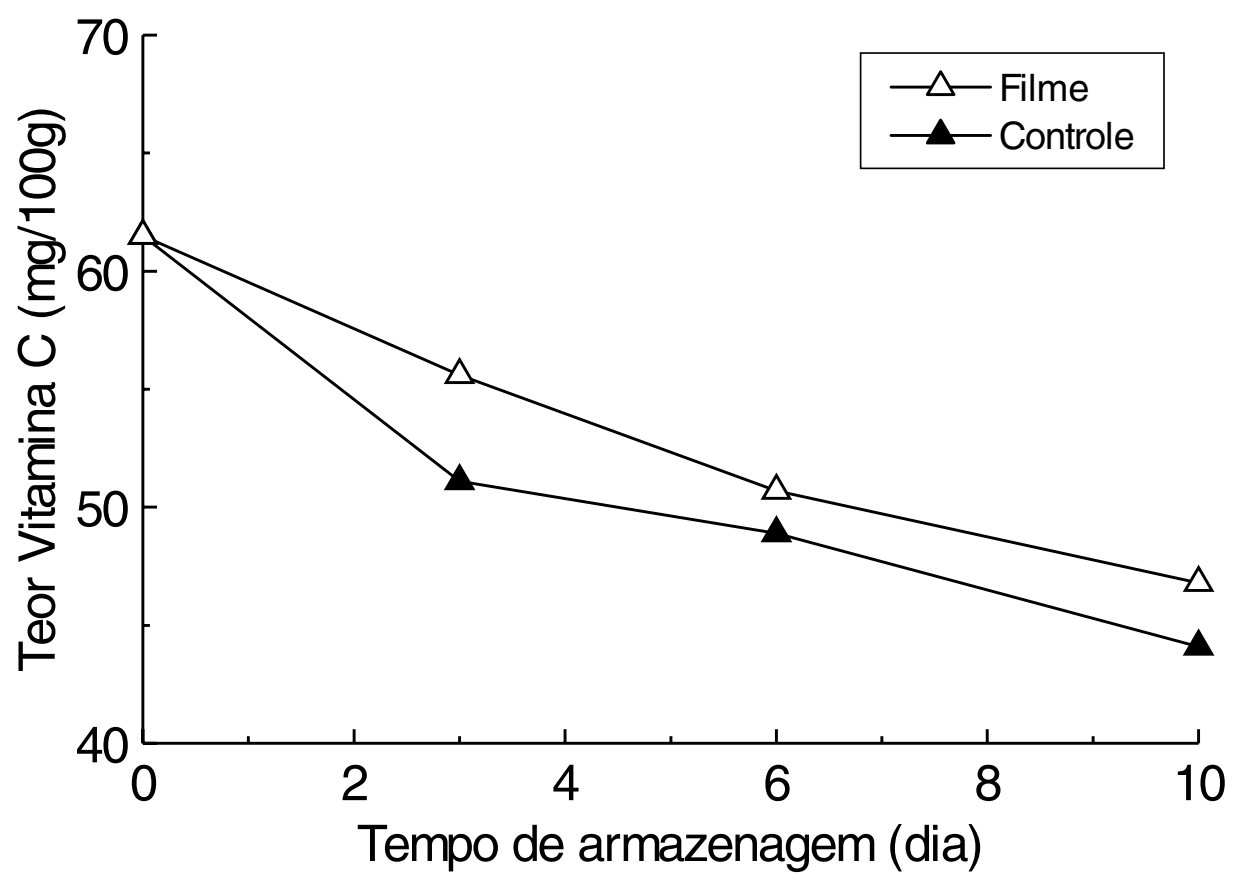

Figura 2. Teor de vitamina $\mathrm{C}$ dos morangos com e sem embalagem de $\mathrm{PVC}$ armazenados a $12^{\circ} \mathrm{C}$. armazenagem, os frutos de ambos tratamentos

Em ambos os tratamentos houve diminuição dos teores de vitamina $\mathrm{C}$, porém no tratamento FILME a diminuição foi menor, o que significa que o estado de conservação dos morangos foi melhor, mantendo suas características fisiológicas e nutricionais.

Cor

Os valores calculados de diferença de cor ("E) entre os morangos no tempo zero e demais tempos de armazenagem estão expressos na Tabela 2, com seus respectivos tratamentos.

A diferença de cor dos morangos embalados aumentou menos que a dos sem embalagem ao longo da armazenagem, provavelmente devido à menor atividade metabólica do fruto que reduziu a formação de antocianinas nos morangos embalados com filme de PVC e também devido à perda de massa que reduziu o valor de $\mathrm{L}^{*}$ das amostras controle. Após
Tabela 2. Diferença de cor ("E) das amostras de morango dos tratamentos FILME e CONTROLE.

\begin{tabular}{ccc}
\hline \multirow{2}{*}{$\begin{array}{c}\text { Tempo } \\
\text { (dia) }\end{array}$} & \multicolumn{2}{c}{$\Delta \mathrm{E}$} \\
\cline { 2 - 3 } & $\begin{array}{c}\text { Tratamento } \\
\text { CONTROLE }\end{array}$ & $\begin{array}{c}\text { Tratamento } \\
\text { FILME }\end{array}$ \\
\hline 3 & 2,75 & 3,33 \\
6 & 5,28 & 3,24 \\
10 & 7,34 & 4,81 \\
\hline
\end{tabular}

seis dias de armazenamento, as amostras do tratamento CONTROLE apresentavam coloração vermelho-escuro, a epiderme do fruto estava enrugada e possuía aspecto de estarem murchas, além de possuírem diversos pontos de crescimento visível por bolores. Já as amostras do tratamento FILME apresentavam melhor aspecto visual, sua coloração era vermelha característica de epiderme de morangos e não apresentavam sinal visível de deterioração microbiológica. Após dez dias de 
apresentavam crescimento visível de bolores, porém os morangos embalados possuíam coloração menos intensa, apresentando melhor aspecto visual.

\section{Conclusão}

A embalagem utilizando filme de PVC aumentou a vida de prateleira de morangos em relação aos sem embalagem pois preservou melhor a coloração característica do produto e teor de vitamina $\mathrm{C}$ e reduziu as taxas de respiração e de perda de massa, caracterizando a embalagem como sendo adequada para este tipo de produto.

\section{Agradecimentos}

Os autores agradecem ao Conselho Nacional de Desenvolvimento Científico e Tecnológico (CNPq) pelo auxílio financeiro concedido.

\section{Referências}

AOAC. Official methods of analysis. Washington: Association of Official Analytical Chemists, 1984.

BENASSI, M.T.; ANTUNES, A.J.A. Comparison of metaphosphoric and oxalic acids as extractant solutions for the determination of vitamin $\mathrm{c}$ in selected vegetables. Arquivos de Biologia e Tecnologia, v.31, n.4, p. 507-513, 1998.

CALEGARO, J.M.; PEZZI, E.; BENDER, R.J. Utilização de atmosfera modificada na conservação de morangos em pós-colheita. Pesquisa Agropecuária Brasileira, v.37, n.8, p.1049-1055, 2002.

CHITARRA, M.I.F.; CHITARRA, A.B. Pós-colheita de frutos e hortaliças, fisiologia e manuseio. São Paulo: Ed. Nagy, 1990.320 p.

GOMES, J.C.C. Produção de matrizes de morangueiro por meio de cultura de tecidos. Embrapa Clima Temperado - Sistemas de produção, 7, nov. 2005. ISSN 1806-9207, Versão Eletrônica http://www.cpact.embrapa.br/sistemas/ matrizes_morangueiro/index.htm. Acesso em 09/2005.

INSTITUTO ADOLFO LUTZ. Normas analíticas do Instituto Adolfo Lutz, v.1, 3ed. São Paulo: Instituto Adolfo Lutz, 1985.533p.
JACOMETTI, G.A.; MENEGHEL, R.F.A.; YAMASHITA, F. Aplicação de revestimentos comestíveis em pêssego (Prunus persica). Ciência e Tecnologia de Alimentos, v.23, n.1, p.95-100, 1993.

KADER, A.A. Biochemical and physiological basis for effects of controlled and modified atmospheres on fruits and vegetables. Food Technology, v.40, n.5, p.99-104, 1986.

KLUGE, R.A.; NACHTIGAL, J.C. Fisiologia e manejo póscolheita de frutas de clima temperado. Pelotas: UFPEL, p.19-21, 1997.

KLUGE, R.A.; SCARPARE, F.; ALEXIO, J.; JACOMINO, A.P. Embalagens plásticas para pêssegos 'flordaprince' refrigerados. Scientia Agricola, v.56, n.4, p.843-850, 1999.

NUNES, M.C.N.; BRECHT, J.K.; MORAIS, A.M.M.B.; SARGENT, S.A. Physical and chemical quality characteristics of strawberries after storage are reduced by a short delay to cooling. Postharvest Biology and Technology, v.6, p.17-28, 1995.

PFAFFENBACH,L.B.; CASTRO, J.V.; CARVALHO, C.R.L.; ROSSETTO, C.J. Efeito da atmosfera modificada e da refrigeração na conservação pós-colheita de manga espada vermelha. Revista Brasileira de Fruticultura, v.25, n.3, p.410-413, 2003.

REICHERT, L.J.; MADAIL, J.C.M. Aspectos socioeconômicos. In: SANTOS, A.M.; MEDEIROS, A.R.M. (Ed.) Morango: produção. Pelotas: Embrapa Clima Temperado; Brasília: Embrapa Informação Tecnológica, 2003. p. 12-15. (Frutas do Brasil, 40).

RESENDE, L.M.A.; MASCARENHAS, M.H.T.; PAIVA, B.M. Panorama da produção e comercialização de morango. Informe Agropecuário, v.20, n.198, p.5-19, 1999.

RONQUE, E.R.V. A cultura do morangueiro: revisão e prática. Curitiba: EMATER - PR., 1998.

SARANTOPOULOS, C.I.G.L.; OLIVEIRA, L.M.; CANAVESI, E. Requisitos de conservação de alimentos em embalagens flexiveis. Campinas: CETEA/ITAL, 2001. $215 \mathrm{p}$.

YAMASHITA, F.; TONZAR, A.C.; FERNANDES, J.G.; MORIYA, S.; BENASSI, M.T. Influência de diferentes embalagens de atmosfera modificada sobre a aceitação de uvas finas de mesa var. Itália mantidas sob refrigeração. Ciência e Tecnologia de Alimentos, v.20, n.1, p.110-114, 2000.

YAMASHITA, F.; TONZAR, A.C.; FERNANDES, J.G.; MORIYA, S.; BENASSI, M.T. Embalagem individual de mangas cv. Tommy Atkins em filme plástico: efeito sobre a vida de prateleira. Revista Brasileira de Fruticultura, v.23, n.2, p.288-292, 2001. 
